\title{
Chinical Application of Interferon- $\gamma$ Release Assays for the Prevention of TUberCulosis IN COUNTRIES WiTh LOW INCIDENCE
}

\section{STANDFIRST}

In this article, we discuss the principles and use of IGRAs, and we provide recommendations for their use in countries with low incidence of tuberculosis.

\section{AUTHORS}

Christoph Lange ${ }^{1-5}$, Anna M. Mandalakas ${ }^{6}$, Barbara Kalsdorf ${ }^{1-3}$, Claudia M. Denkinger ${ }^{7}$, and Martina Sester ${ }^{8}$

\section{AFFILIATED INSTITUTIONS}

${ }^{1}$ Division of Clinical Infectious Diseases, Medical Clinic Research Center Borstel, Borstel, Germany ${ }^{2}$ German Center for Infection Research (DZIF), Clinical Tuberculosis Center, Borstel, Germany ${ }^{3}$ International Health/Infectious Diseases, University of Lübeck, Lübeck, Germany ${ }^{4}$ Department of Medicine, Karolinska Institute, Stockholm, Sweden ${ }^{5}$ Department of Internal Medicine, University of Namibia School of Medicine, Windhoek, Namibia ${ }^{6}$ Global Tuberculosis Program, Department of Pediatrics, Baylor College of Medicine, Houston, Texas, United States ${ }^{7}$ FIND, Geneva, Switzerland ${ }^{8}$ Department of Transplant and Infection Immunology, Saarland University, Homburg, Germany

\section{CORRESPONDING AUTHOR}

Christoph Lange

Clinical Infectious Diseases

Research Center Borstel

Borstel, Germany

clange@fz-borstel.de
DOI

10.20411/pai.v1i2.173 


\section{ABSTRACT}

Despite global efforts to control tuberculosis (TB) the estimated number of people who developed TB worldwide increased to an all-time record of more than 10 million in 2015. The goal of the World Health Organization (WHO) to reduce the global incidence of TB to less than 100 cases per million by 2035, cannot be reached unless TB prevention is markedly improved. There is a need for an improved vaccine that better protects individuals who are exposed to Mycobacterium tuberculosis from infection and active disease compared to the current $M$. bovis Bacille Calmette Guérin (BCG) vaccine. In the absence of such a vaccine, prevention relies on infection control measures and preventive chemotherapy for people with latent infection with M. tuberculosis (LTBI), who have the highest risk of progression to active TB. During the past decade, interferon- $\gamma$ release assays (IGRAs) have increasingly replaced the tuberculin skin test as screening tools for the diagnosis of LTBI in countries with a low incidence of TB. Despite recent WHO guidelines on the management of LTBI, the definition of groups at risk for TB remains controversial, and the role of IGRAs for TB prevention in low-incidence countries remains uncertain. We reviewed the scientific literature and provide recommendations for the use of IGRAs for LTBI diagnosis in low-incidence countries. These recommendations are based on the number of patients needing treatment in order to prevent one case of TB. As the positive predictive value of IGRAs for the development of TB is sub-optimal, research must focus on the identification of alternative biomarkers that offer better predictive ability in order to substantially reduce the number needing treatment while improving the prevention of TB and improving the effectiveness of targeted preventive chemotherapy.

Keywords: Interferon- $\gamma$ release assays, IGRAs, tuberculin skin test, tuberculosis, $M$. tuberculosis, immunodeficiency, number needed to treat, risk groups, QuantiFERON, T-SPOT.TB.

\section{INTRODUCTION}

Tuberculosis (TB) is an airborne infectious disease caused by Mycobacterium tuberculosis [1]. The World Health Organization (WHO) estimates that 10.4 million people developed TB and 1.8 million people died from this disease in the year 2015 [2] . Although the annual number of deaths attributed to TB is declining, TB has now surpassed HIV-infection as the leading cause of mortality by a particular microorganism worldwide []ㅡ.

Infection with $M$. tuberculosis is transmitted by inhalation of bacilli containing nucleic droplets which are released into the air from patients with pulmonary TB when coughing [4]. Chronic fibro-nodular or fibro-cavitary pneumonia is the predominant clinical manifestation of this disease, and the most common extra-pulmonary manifestation of TB is lymphadenitis. Tuberculosis can potentially involve every organ of the human body []ㅡ, and the risk of extrapulmonary manifestations is inversely related to age [6]. The great majority of people infected with M. tuberculosis do not develop active disease although it is estimated that one third of the world's population is infected with M. tuberculosis. [2]

In general, the risk for the development of TB increases with exposure to M. tuberculosis and along a gradient of immunodeficiency. Inherited susceptibility to mycobacterial infections []], HIV-infection [ $\underline{8}$ ], treatment with tumor necrosis factor (TNF) antagonists [9]], and young age [10] carry the greatest risk for the development of TB after exposure. 
Despite the enormous burden of TB on many healthcare systems and the dramatic emergence of drug-resistant tuberculosis during the past decade, the WHO recently proposed ambitious targets of reducing the numbers of deaths due to TB from 2015 to 2035 by $95 \%$ and the incidence of TB by $90 \%$. Part of the WHO's "END TB Strategy" is the elimination of TB by the year 2050 [11].

In addition to improving treatment outcomes of $\mathrm{TB}$, especially multidrug-resistant and extensively drug-resistant TB, the prevention of TB must be substantially improved to achieve these goals $[\underline{12}, \underline{13}]$. In the absence of a vaccine that is more effective than M. bovis BCG to prevent infection with $M$. tuberculosis and the development of active TB, the prevention of TB relies on 1) early case detection and adequate treatment (treatment as prevention), 2) reduction of transmission by isolation of infectious cases and other infection control measures, and 3) identification and preventive treatment of individuals with latent infection with M. tuberculosis (LTBI) [14].

\section{LATENT INFECTION WITH MYCOBACTERIUM TUBERCULOSIS: A CONCEPT FOR CLINICIANS}

Latent infection with $M$. tuberculosis (LTBI) cannot be measured directly. In clinical practice, LTBI is defined by the presence of an $M$. tuberculosis-specific adaptive immune response in the absence of signs and symptoms of active TB [15]. People with LTBI are at risk for developing active TB, and the risk depends on the degree of $M$. tuberculosis exposure and the degree of immunodeficiency. Preventive treatment of persons with LTBI can avert the development of active TB. Treatment may be comprised of one of the following regimens: isoniazid for 6 months, isoniazid for 9 months, rifapentine (weekly) for 3 months (available in most of Europe via an international pharmacy) plus isoniazid, isoniazid for 3 to 4 months plus rifampicin, or rifampicin alone for 3 to 4 months [16]. However, screening for LTBI and preventive treatment must be targeted to highrisk groups to remain cost effective.

The tuberculin-skin-test (TST) has been the standard method for the diagnosis of LTBI for more than a century. The development of this test followed the discovery by von Pirquet in 1907 (the test was later revised by Mendel [17] and Mantoux [18]) that an antigen-specific delayed type hypersensitivity reaction can be provoked by intradermal inoculation of sterile supernatants of $M$. tuberculosis cultures to stimulate $M$. tuberculosis-specific adaptive immune responses in vivo,

In the first study of the TST, von Pirquet made 3 important observations that are still valid [19]: Firstly, neonates with active TB have negative TST results as their adaptive immune system is not yet developed. Secondly, in adolescents (the same is true for adults), the sensitivity of the TST for the diagnosis of active TB is approximately $60 \%$. Thirdly, in countries with a high incidence of TB, one third of the adolescent population has LTBI.

The TST has technical and operational disadvantages which include cross-reactivity to M. bovis or non-tuberculous mycobacteria (NTM) after BCG vaccination or NTM infection, requirement of a second visit 48 to 72 hours after application of the skin test, operator variability in test reading, low sensitivity in immunocompromised patients, and a booster effect that can be misinterpreted as a recent conversion. This has led to the development of interferon- $\gamma$ release assays (IGRAs) as ex-vivo alternatives. Two IGRAs are commercially available. Both rely on the principle that blood cells are stimulated ex vivo with mycobacterial antigens, which are processed and presented by antigen-presenting cells. T-cells from individuals with prior sensitization recognize mycobacterial antigens, leading to activation and cytokine induction [15]. IFN- $\gamma$ is commonly used as a read- 
out cytokine. In the QuantiFERON-TB Gold in-tube assay (Qiagen, Hilden, Germany), IFN- $\gamma$ is detected in supernatants of stimulated whole blood samples using an enzyme-linked immunosorbent assay (ELISA). However, the T-SPOT.TB assay (Oxford Immunotech, Abingdon, UK) quantifies IFN- $\gamma$ producing cells from isolated peripheral blood mononuclear cells (PBMC) using the enzyme-linked immunospot (ELISPOT) assay principle. Advantages of the IGRAs include shorter stimulation times of 18 to 24 hours only. Moreover, unlike in TST, where stimulation is performed with tuberculin purified protein derivative (PPD), IGRAs use stimuli such as early secreted antigenic target (ESAT)-6 and culture filtrate protein (CFP)-10 that are specific for M. tuberculosis due to their absence in $M$. bovis BCG and most NTM. Therefore, IGRAs have a higher specificity to distinguish immunity from $M$. bovis BCG infection or NTM infection from true LTBI or active TB. Moreover, IGRAs are accompanied by negative and positive control stimuli. Indeterminate test results due to failure to react in the positive control (phytohemagglutinin, PHA) have been associated with young age due to immaturity of the immune system $[\underline{20}, \underline{21}]$ and to the extent of immunodeficiency [ $\underline{8}$ ]. Similarly, if reactivity in the negative control stimulation is similar to the specific stimulation, this result is considered indeterminate, as the response may not be assigned specificity for mycobacterial antigens, and thereby false positive results are avoided. As compared to the TST, reactivity of the positive control may allow better distinction between true negative results from indeterminate tests, which represents an advantage of IGRAs over the TST [22-25]. Finally, IGRAs have a similar or higher sensitivity compared to the TST, especially when used in immunocompromised patients with T cell-mediated immunodeficiencies such as HIV-infected patients, or stem-cell or solid organ transplant recipients $[\underline{8}, \underline{15}, \underline{26}, \underline{27}]$. However, the sensitivity of both tests decreases with increasing severity of immunodeficiency, which also negatively affects the ability to predict progression towards tuberculosis.

Based on the peptide composition, CD4 T cells are the prominent subpopulation that reacts in the 2 commercial assay formats. As an attempt to further increase sensitivity, the "QuantiFERON plus" assay has recently been released which includes an additional tube containing both the CD4 T-cell stimulating peptides derived from ESAT-6 and CFP-10 as well as CFP-10-derived shorter peptides designed to stimulate CD8 T cells. The difference in the level of IFN- $\gamma$ secretion between the 2 tubes may be considered as a surrogate for CD8 T-cell reactivity. First results with the QFT plus assay may indicate a higher sensitivity for detection of active TB [28], and a better association with risk factors for recent exposure among contacts [28] as compared to the QuantiFERON-TB Gold In-Tube test. Recently, skin-test formats have been further developed that make use of ESAT-6 and CFP-10 as in vivo stimuli [29-32]. As expected, this leads to an increase in specificity compared to the conventional TST. The Diaskintest is already widely used in Eastern Europe and Russia, while the c-TB skin test is still under clinical evaluation. Although sensitivity is not likely to improve, the performance of these skin-tests in immunocompromised individuals warrants further study. The properties of the skin-tests and the IGRAs are summarized in Table 1. Common misconceptions and frequently asked questions about IGRAs are stated in Table 2. 
Table 1. Comparison of immunodiagnostic test characteristics

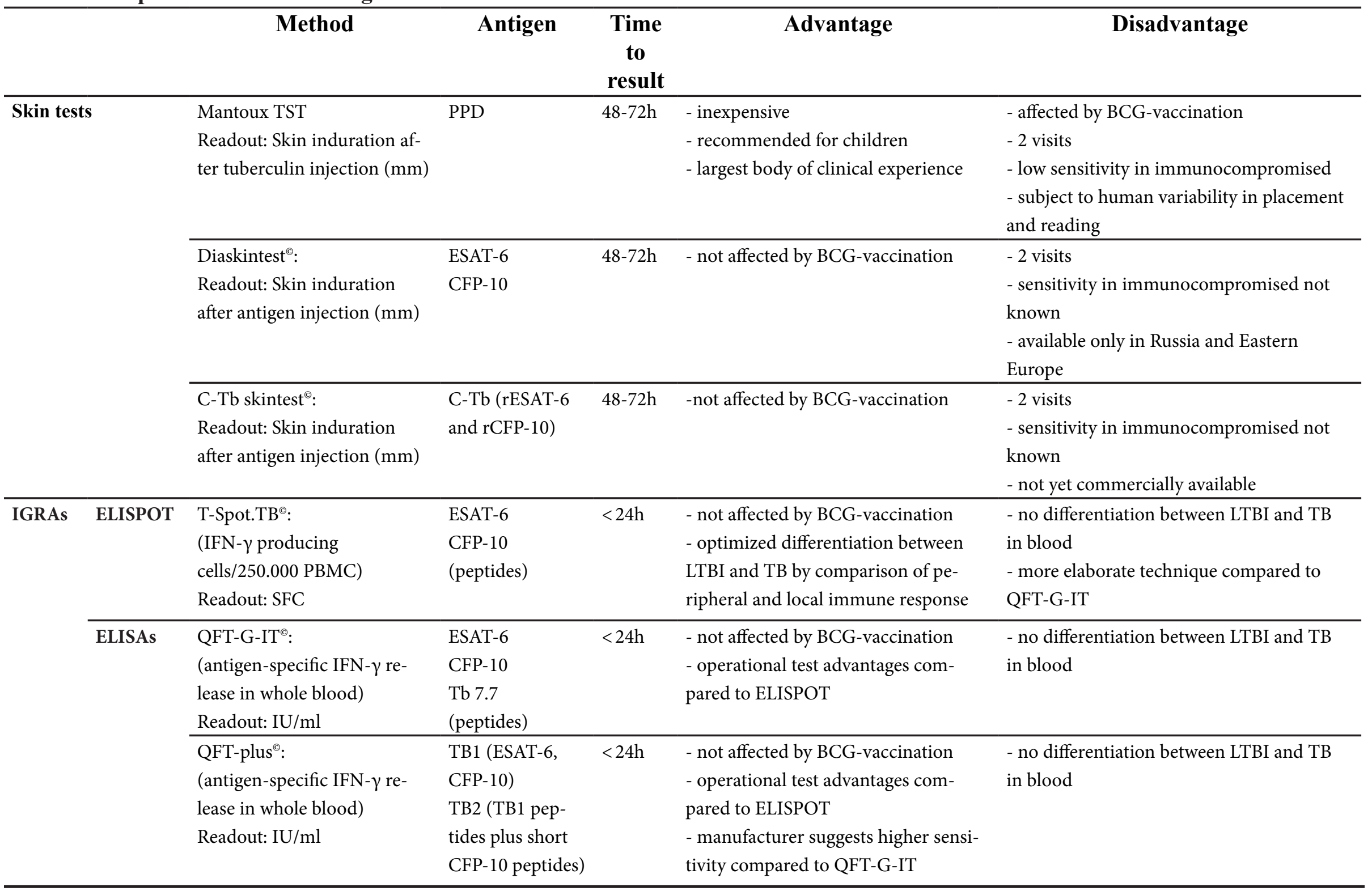

BCG, Bacille Calmette-Guérin; CFP-10, culture filtrate protein; ESAT-6, early secreted antigenic target; IFN- $\gamma$, interferon- $\gamma$; PPD, purified protein derivative; PBMC, peripheral blood mononuclear cells; TST, tuberculin skin test. 


\section{Table 2. Ten common misconceptions about IGRAs}

\section{Misconception}

1 "IGRAs are tests for the diagnosis of active TB."

\section{Evidence}

The pooled sensitivities and specificities for the diagnosis of active TB of the Quantiferon-Gold-in tube test and the T-Spot-TB test were $80 \%$ (95\% CI 75- 84\%)/ 79\% (95\% CI 75-82\%) and 81\% (95\% CI 78-84\%)/59\% (95\% CI 56-62\%)

In a recent systematic-review and meta-analysis [33]. The diagnostic accuracy is higher, when IGRAs are performed on extrasanguinous fluids, e.g. CSF, ascites, BAL [33, 34]. Standard IGRAs performed with cells from the peripheral blood should not be used for the diagnosis of active TB. In active TB approximately $20 \%$ of patients have a negative IGRA test result [35].

2 "A negative IGRA test result excludes active TB."

While the negative predictive value of IGRAs is very high when healthy contacts are evaluated, the negative predictive value is low in HIV-infected hosts. More than $50 \%$ of HIV-infected individuals who later developed active TB in low incidence countries of TB had a negative test results in both IGRAs at the time of screening []ㅛ.

In the largest prospective multicenter observational cohort study that evaluated the role of IGRAs and the TST as predictors for progression to active TB in immunocompromised hosts, prediction of disease progression by IGRA was not superior to the TST [8] immunocompromised patients."

5 "The higher the concentration of IFN- $\gamma$ in the QFT-G-IT test or the number of spot-forming cells in the T-SPOT.TB test, the greater the risk for the progression to active TB."

The cut-offs for test-positivity provided by the manufacturers of the QFT-GIT and the T-SPOT.TB test have been validated in at least one prospective study including more than 5000 close contacts of patients with active TB. In contrast to previous smaller studies, in this multinational study in Europe, there was no correlation between the magnitude of a positive test and the risk for progression to tuberculosis [ $[66]$.

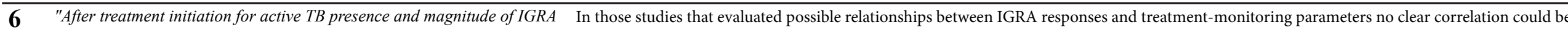
responses reflect the response to anti-TB therapy, thus IGRAs can be used found [37-40].

for treatment monitoring."

7 "Positive IGRA responses that develop after anti-TB vaccination are an indicator for protective immunity against TB."

In a large placebo controlled prospective randomized trial evaluating a novel MVA-Ag85 vaccine, $M$. tuberculosis specific immune responses could be detected by IGRA in the group of MVA-Ag85 vaccinated children, but not in the placebo group. During follow-up, the TB incidence was similar on the MVA-Ag85 vaccine and in the placebo arm, suggesting that IGRAs are not correlate markers of protective immunity against TB [41]].

$8 \quad$ "Health-care workers in low-incidence countries of TB should undergo regular IGRA screening."

9 "A positive IGRA result carries the same risk for the development of tuberculosis in different groups of patients or healthy individuals."

In 3 recent studies where health-care workers were tested by IGRAs in low-incidence countries of TB and followed for $>2$ years not a single case of TB occurred among > 1500 IGRA positive healthcare workers in the absence of preventive chemotherapy [42-44]. The risk of healthcare workers for the development of TB is low, unless a specific intensive contact to a TB patients occurred. Regular screening is not justified.

The positive predictive values of IGRAs and the number needed to treat to prevent one case of tuberculosis based on IGRA results show substantial differences among different groups of individuals. In persons with HIV infection and ongoing viral replication [ㅍ] ] or in small children who are household contacts [36], the number needed to treat to prevent one case of TB is approximately 10, thus IGRA screening followed by preventive chemotherapy is highly effective. In persons from low-incidence countries of TB with chronic renal failure 1/ 4 persons has a positive IGRA test result but the risk for TB is very low [8] , Regular screening and preventive chemotherapy is not indicated in this group.

10 "Indeterminate test results are always caused by immunodeficiency"
While failure of the positive control is the most common cause of an indeterminate IGRA test result, failure of the negative control may also be a cause of an indeterminate test result [8], most commonly in persons with autoimmune disorders (e.g. Systemic lupus erythematodes). 
How well is the progression to tuberculosis predicted by IGRAs in countries with a low incidence of TB? Recommendations to use IGRAs in countries with a low incidence of TB are restricted to asymptomatic individuals who have an increased risk for progression towards tuberculosis, and for the purpose of guiding preventive chemotherapy. According to WHO guidelines, individuals at risk include close contacts of patients with active TB, migrants, health care workers, patients with diabetes, and immunocompromised patients with HIV infection, chronic renal failure or receiving immunosuppressive drug therapy, treatment with TNF antagonists or other biological therapeutics [ㄷ]. Although IGRAs have a high specificity and good sensitivity for diagnosing latent or active infection with $M$. tuberculosis, several studies from countries with low incidence of TB have shown that only a very small percentage of individuals with positive test results develop active TB, and the risk for progression differs among the groups considered at risk [ $\underline{8}, \underline{33,36,42,43,47-50]}$. Moreover, patients with severe immunodeficiency who develop TB may have had negative test results at the time of screening, which emphasizes that the negative predictive value is not sufficient in this situation []․ The ability of IGRAs to predict progression towards TB in various risk groups from low-incidence countries was extracted from recently published key studies with sample sizes of more than 1000 individuals, and performance characteristics are summarized in Table 3. We have also included a study in migrant contacts to show comparative data for this risk group. Although the selection of studies was not based on a formal systematic review, the focus on analyses with large sample size mostly derived from multicenter analyses allows for a representative estimation of IGRA performance in current clinical practice. Although the risk for the development of TB is highest in the first year following contact with $M$. tuberculosis and the follow-up time in these studies was between 2-5 years, some individuals may develop TB at a later time. Therefore, results from these studies may underestimate the long-term risk for the development of tuberculosis.

The number needed to treat (NNT) to prevent one case of TB is a clinically useful parameter based on test results to guide preventive chemotherapy in a given risk group. It is based on the absolute risk reduction (1/absolute risk reduction), and is calculated from the difference in the number of TB cases found on follow-up in individuals with positive test results between groups with and without preventive chemotherapy. Recently, several large studies with more than a 1000 individuals each have been published that allow a robust estimation of the NNT for various groups considered at risk. A large European multicenter study performed in the TuBerculosis Network European Trialsgroup (TBNET; www.tb-net.org) included 4513 close contacts of patients with active tuberculosis who were screened with either QFT-G-IT or the T-SPOT. TB assay [36]. The diagnosis of tuberculosis was overall a rare event with only 24 incident cases. The incidence of tuberculosis was substantially lower in contacts with preventive chemotherapy, indicating that treatment was highly effective. Also, the negative predictive value was nearly $100 \%$, emphasizing that tuberculosis is rare in IGRA-negative contacts. Nevertheless, the positive predictive value of a positive IGRA was low (1.9 and 0.7 for QFT-G-IT or the T-SPOT.TB), which shows that the majority of contacts with positive IGRA did not develop TB. Taking these results together and based on this study, the NNT to prevent one case of TB is 37 for QFT-G-IT and 37 for the T-SPOT.TB (Table 3) [ㅌ6]. Interestingly, these NNTs are very similar to those derived from another contact-tracing study involving 1579 subjects in Germany [47], where the NNT for the QFT-G-IT was 34. Finally, in a large Dutch study, where 4716 contacts were screened using a TST and/or IGRA, the NNT reached 89. Interestingly, if screening was restricted to close contacts, this led to a substantial decrease in the NNT to 30 (Table 3) [48]. 
Table 3. Numbers needed to treat to prevent one case of TB in people with a positive IGRA or TST test result in different risk-groups in low incidence countries

\begin{tabular}{|c|c|c|c|c|c|c|c|c|c|c|c|}
\hline Study & Country & Population & LTBI test & $\begin{array}{c}\text { LTBI } \\
\text { positive (\%) }\end{array}$ & $\begin{array}{l}\text { Number followed } \\
\text { longitudinally }\end{array}$ & $\begin{array}{l}\text { TB cases } \\
\text { incident }\end{array}$ & $\begin{array}{l}\text { Sensitivity } \\
\%\end{array}$ & $\begin{array}{l}\text { Specificity } \\
\%\end{array}$ & $\begin{array}{l}\text { PPV } \\
\%\end{array}$ & $\begin{array}{l}\text { NPV } \\
\%\end{array}$ & NNT \\
\hline 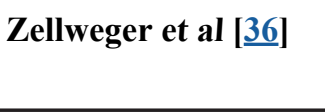 & Europe & contacts & QFT-G-IT & $1067(27.4 \%)$ & 3425 & 20 & 85.0 & 74.0 & 1.9 & 99.9 & 37 \\
\hline Geis et al [ㅍ] & Germany & contacts & QFT-G-IT $^{\mathrm{t}}$ & $306(19.3 \%)$ & 254 & 6 & 100 & n.d. & 2.5 & n.d. & 34 \\
\hline \multirow[t]{2}{*}{ Sloot et al [표 } & \multirow[t]{2}{*}{ Netherlands } & contacts & $\begin{array}{l}\text { TST/QFT-G- } \\
\text { IT }\end{array}$ & $739(15.5 \%)$ & 4716 & 17 & 76.5 & 85.8 & 1.9 & 99.9 & 89 \\
\hline & & $\begin{array}{l}\text { Close } \\
\text { contacts }\end{array}$ & $\begin{array}{l}\text { TST/QFT-G- } \\
\text { IT }\end{array}$ & & 1622 & 10 & 90 & 79 & 2.6 & 99.9 & 30 \\
\hline \multirow[t]{3}{*}{ Kik et al [1ㅣ] } & \multirow[t]{3}{*}{ Netherlands } & \multirow{3}{*}{$\begin{array}{l}\text { Migrant } \\
\text { contacts }\end{array}$} & TST $^{\mathrm{d}}$ & 339 & 339 & 8 & 87.5 & n.d. & 3.8 & n.d. & 26 \\
\hline & & & QFT-G-IT & 178 & 327 & 8 & 62.5 & n.d. & 2.8 & n.d. & 36 \\
\hline & & & T-SPOT.TB & 181 & 299 & 8 & 75 & n.d. & 3.3 & n.d. & 30 \\
\hline Hermansen et al [49] & Denmark & Mixed $^{\mathrm{a}}$ & QFT-G-IT & $1703(10.7 \%)$ & 15980 & 40 & 50 & 88.7 & 1.32 & 99.9 & $68^{e}$ \\
\hline \multirow[t]{8}{*}{ Sester et al $[\underline{8}]$} & \multirow[t]{8}{*}{ Europe } & \multirow{3}{*}{$\begin{array}{l}\text { Immuno-com- } \\
\text { promised }^{b}\end{array}$} & TST & $212(14.1 \%)$ & 1404 & 6 & 50 & 86.2 & 1.5 & 99.8 & 50 \\
\hline & & & QFT-G-IT & $239(15.6 \%)$ & 1342 & 4 & 50 & 84.1 & 0.9 & 99.8 & 80 \\
\hline & & & T-SPOT.TB & $266(17.7 \%)$ & 1310 & 6 & 50 & 81.3 & 1.3 & 99.7 & 64 \\
\hline & & \multirow[t]{2}{*}{ HIV only } & TST & $55(8.7 \%)$ & 626 & 6 & 50 & 93.7 & 7.1 & 99.5 & 14 \\
\hline & & & T-SPOT.TB & $101(15.9 \%)$ & 561 & 6 & 50 & 89 & 4.7 & 99.4 & 21 \\
\hline & & \multirow{3}{*}{$\begin{array}{l}\text { HIV } \\
\text { positive } \\
\text { HIV load }\end{array}$} & TST & $24(8.1 \%)$ & 291 & 6 & 50 & 92.6 & 12.5 & 98.9 & 8 \\
\hline & & & QFT-G-IT & $25(8.4 \%)$ & 289 & 4 & 50 & 91.9 & 8 & 99.2 & 13 \\
\hline & & & T-SPOT.TB & $31(10.4 \%)$ & 255 & 6 & 50 & 88.8 & 9.7 & 98.7 & 10 \\
\hline 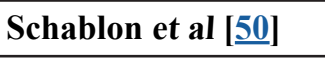 & Germany & HCW & QFT-G-IT & $317(8.3 \%)$ & 3823 & 0 & 0 & 91.7 & 0 & 100 & n.a. ${ }^{f}$ \\
\hline Slater et al [43] & USA & HCW & QFT-G-IT & $853(9.3 \%)$ & 9153 & 0 & 0 & 90.7 & 0 & 100 & n.a. ${ }^{\mathrm{f}}$ \\
\hline \multirow[t]{3}{*}{ Dorman et al [42] } & USA & HCW & TST & $125(5.2 \%)$ & 2418 & 0 & 0 & 94.8 & 0 & 100 & n.a. ${ }^{\mathrm{f}}$ \\
\hline & & & QFT-G-IT & $118(4.9 \%)$ & 2418 & 0 & 0 & 95.1 & 0 & 100 & n.a. ${ }^{\mathrm{f}}$ \\
\hline & & & T-SPOT.TB & $144(6.0 \%)$ & 2418 & 0 & 0 & 94 & 0 & 100 & n.a. ${ }^{\mathrm{f}}$ \\
\hline
\end{tabular}

aindividuals included contacts, patients prior to TNF antagonist treatment, and TB suspects; bindividuals included patients with chronic renal failure, patients prior to TNF antagonist treatment, solid organand stem cell transplant recipients, and HIV infected patients; PPV, positive predictive value; NPV, negative predictive value; NNT, number needed to treat to prevent a case of TB; LTBI, latent infection with M. tuberculosis; TST, tuberculin skin test; QFT-G-IT, QuantiFERON gold in tube; HCW, health-care workers; PPV and NPV were calculated from all individuals with and without preventive chemo-

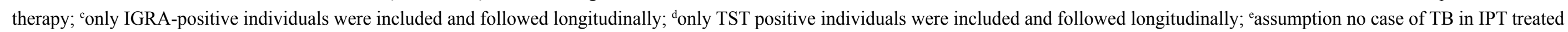
individuals, $35 \% \mathrm{INH}$ coverage among test positives; f ${ }^{\text {no }}$ cases of active TB. 
Together these findings illustrate that the NNT among contacts is in the range of 30 to 37, and that this NNT-range may be achieved if screening is focused on close contacts (Table 3 ). The NNT may be considerably higher if individuals from several risk groups are estimated together. This is illustrated by a nation-wide study from Denmark which included 15980 individuals after contact tracing, screening prior to TNF antagonist treatment, or suspected of having TB. In this study, 40 incident TB cases were observed, and the PPV of a positive QFT-G-IT was 1.32 only with an estimated NNT of 68 [워]. Interestingly, this corresponds to the higher NNT calculated from a large multicenter study among immunocompromised patients including HIV-infected individuals, patients with chronic renal failure or rheumatoid arthritis, or stem-cell and solid organ transplant recipients []. In the combined analysis of all patients, the NNT was 50 for the TST, 80 for the QFT-G-IT, and 64 for the T-SPOT.TB assay. It should be noted that for immunocompromised patients the NNT was higher with the use of IGRAs than with the use of TST. In addition, TB cases also occurred in patients who tested negative with IGRA/TST and were almost exclusively found among HIV-infected patients; all HIV-patients developing TB had ongoing HIV replication $[\underline{8}, \underline{45}]$. Thus, targeted preventive therapy for immunocompromised hosts in low TB incidence countries is most effective in HIV-infected patients with detectable viral replication (NNT of 8 for the TST, 13 for the QFT-G-IT, and 10 for the T-SPOT.TB assay, (Table 3) [노, 52].

Health-care workers represent another group of individuals where serial monitoring has been recommended due to a presumed higher risk for disease progression. However, as emphasized by 3 large studies from Germany and from the United States involving single or serial screening of more than 15000 individuals, no case of tuberculosis occurred (Table 3) [42, 43, 50], which may suggest that serial screening of health-care workers should not be performed and should be restricted to personnel after close contact with a patient with active TB. Alternative definitions of IGRA conversion and different cutoff points for different risk populations should be developed [3] . These would need to be evaluated in large data sets and modeling studies [ $\underline{43}, \underline{54}]$.

Finally, screening is recommended for migrants. A study from the Netherlands analyzed progression towards TB in approximately 300 migrant contacts of cases with active TB [51]. Although progression towards TB in those with negative tests was not reported, the estimated NNT of migrants who had active TB contacts was similar to other contacts with active TB cases (26 for the TST, 37 for the QFT-G-IT, and 30 for the T-SPOT.TB test) (Table 3).

Taken together, a comparison of the NNTs of these studies from countries with a low incidence of TB indicates that the risk for progression differs from one group to another. Moreover, as illustrated by the lowest NNT in close contacts or migrant contacts, or in HIV-infected individuals with ongoing HIV-replication, targeted screening of individuals with additional, clinical risk factors can lead to a substantial decrease in screening load and unnecessary preventive chemotherapy. Similarly, in other groups previously considered at risk such as health-care workers or patients with chronic renal failure, where general LTBI testing was recommended, screening [46] and treatment may now be focused on individuals with additional risk factors.

The benefits of preventive chemotherapy also have to be weighed against age-related drug-associated hepatoxicity $[\underline{55}, \underline{56}]$, and the complexity of such trade-offs might be best judged by data-driven algorithms [57]. Table 4 provides recommendations based on available evidence for the NNT regarding the use of IGRAs and preventive chemotherapy in countries with low incidence of TB. 
Table 4. Recommendations for the use of IGRA-testing* and preventive chemotherapy against active tuberculosis in low-incidence countries according to the number needed to treat to prevent one case of TB.

\begin{tabular}{|c|c|c|}
\hline Recommended & Conditionally recommended & Not recommended \\
\hline $\begin{array}{l}\text { People living with HIV (especially with ongoing viral } \\
\text { replication) }{ }^{\mathrm{a}}\end{array}$ & Solid organ transplant recipients ${ }^{\mathrm{c}}$ & Health-care workers $^{\mathrm{d}}$ \\
\hline Child and adult contacts of pulmonary TB cases ${ }^{\mathrm{a}}$ & Stem- cell transplant recipients ${ }^{\mathrm{c}}$ & Illicit drug users ${ }^{\mathrm{e}}$ \\
\hline Migrants originating from high incidence countries ${ }^{\mathrm{a}}$ & Patients with chronic renal failure ${ }^{c}$ & Homeless people $e^{\mathrm{e}}$ \\
\hline \multirow[t]{5}{*}{$\begin{array}{l}\text { Patients receiving tumor necrosis factor (TNF)- antago- } \\
\text { nist therapy }{ }^{b}\end{array}$} & $\begin{array}{l}\text { HIV-negative patients with other immunodeficiencies not } \\
\text { mentioned above }^{c}\end{array}$ & Patients with diabetes mellitus ${ }^{\mathrm{e}}$ \\
\hline & Patients with silicosis ${ }^{c}$ & Prisoners $^{\mathrm{e}}$ \\
\hline & & People with alcohol abuse ${ }^{\mathrm{e}}$ \\
\hline & & Tobacco smokers ${ }^{\mathrm{e}}$ \\
\hline & & Underweight people $\mathrm{e}^{\mathrm{e}}$ \\
\hline
\end{tabular}

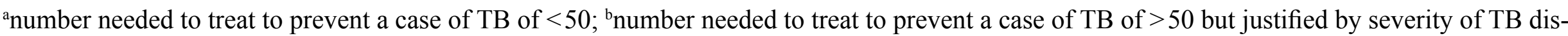
ease; ' number needed to treat to prevent a case of TB of $>100$; at least one additional risk factors for LTBI should be present; ${ }^{d}$ number needed to treat to prevent a case of TB of $>>100$ or ${ }^{~}$ not known but perceived to be high; unless other factors leading to strong or conditional recommendations are present; "the best method is to combine IGRA/TST results with a risk/benefit assessment performed by algorithms [57]. 
Screening for LTBI is currently also recommended and frequently used in other patients considered at risk such as patients prior to TNF antagonist treatment or receiving other immunotherapies for neoplastic, hematologic, rheumatologic, dermatologic, and other conditions. Similar studies with large sample sizes are also needed to define the NNTs for these groups. Additional information for the use of IGRAs and preventive chemotherapy in countries with high or intermediate incidence of TB, where IGRAs are generally not recommended to screen for LTBI, is provided in an appendix.

\section{Are the proposed IGRA cutoffs valid?}

Based on the comparison between healthy controls and patients with culture-confirmed TB, the following cutoffs were established for the 2 commercially available IGRAs: a positive T-SPOT.TB result is defined as antigen-specific induced IFN- $\gamma$ secretion of more than 5 spot forming cells (SFC) per 250000 PBMC after subtraction of the negative control reactivity [58], with a borderline zone between 5 and 7 SFC defined for use in the United States. The result of the QFT-G-IT assay is defined as positive above a cutoff of $0.35 \mathrm{IU}$ IFN $-\gamma / \mathrm{ml}$ whole blood after subtraction of the nil control $[\underline{59}, \underline{60}]$. For the purpose of sensitivity, low cutoffs were assigned in order not to miss any cases.

Reproducibility studies have identified some inter-test variability [그. This may be due to variability in the individual immune function. Moreover, variations might be due to the time of blood collection [61], delay or differences in processing, or duration of incubation. Important immunological sources might be inadequate disinfection before phlebotomy or previous TST boosting.

These variations have most impact if quantitative IGRA results are close to the cutoffs. Serial examinations showed conversion rates between $2.8 \%$ and $8.3 \%$ and very high reversion rates between $37.3 \%$ and $64.8 \%[\underline{42,43,50,62]}$. This has led some authors to propose borderline definition for positivity to avoid unnecessary chest-X-ray or preventive treatment [444].

Although both IGRAs give quantitative results, clinical decisions are based on qualitative results. One study suggested that an increase in the cutoff value may increase the positive predictive value to predict disease progression and decrease the NNT to prevent a single case [47]. However, these results were not confirmed in a larger study [36], where the currently recommended cutoffs for test positivity provided the best discrimination between those who did and did not progress to active tuberculosis [36]. While these cutoffs appear to be optimal for the TB risk evaluation among contacts, it must be acknowledged that a larger proportion of patients with immunodeficiencies who progress to TB, may have negative IGRA test results at the time of screening [

\section{Are IGRAs tools to monitor tuberculosis treatment responses or surrogates for vaccine effectiveness?} The IGRAs measure the response of circulating effector T-lymphocytes to viable and dormant mycobacteria [ $\underline{63}]$, and results are assumed to correlate with the antigenic load present in the body $[37,39,64]$. Treatment and decrease of antigenic load therefore should result in a decrease in IGRAs reactivity, which could conceivably be used for treatment monitoring [녀-66].

\section{Active TB}

Few studies have tried to correlate the changes in IFN- $\gamma$ responses in IGRAs with established

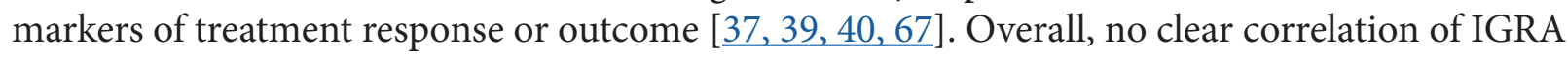


response with treatment-monitoring parameters could be found. This is probably attributable in part to significant within-subject variability in sequential measurements due to both exogenous (eg, relating to test procedure) and endogenous (eg, co-infections, time from exposure) factors [묘].

\section{LTBI}

While there are established markers for treatment monitoring in active TB (ie sputum and smear conversion), no biomarker is currently available for the monitoring of latent TB treatment success. By definition, no mycobacterial product is identifiable in LTBI with current techniques, and therefore a reliance on immune-based tests for monitoring is even greater [ $\underline{69}]$. However, a significant change using an IGRA has been proven difficult to detect probably because (i) IFN- $\gamma$ is produced in low quantity and mostly in close proximity to the antigen [70-71]; (ii) changes in IFN- $\gamma$ response independent of treatment have been observed, which might reflect self-clearance or transition of bacteria into dormancy [2] ; (iii) an initial increase in IFN- $\gamma$ response due to increased antigen stimulation from destruction of mycobacteria can be observed early in treatment [73]. Overall it can be stated that IGRAs do not appear to be a promising biomarker for treatment monitoring in LTBI.

Recently IGRAs were used to describe vaccine-induced cytokine immune responses following a MVA-85 vaccine-specific stimulation in neonates [1]. In this study, induction of a vaccine-specific IGRA response did not correlate with improved capacity to control mycobacterial growth and to protect individuals from active TB.

\section{Special considerations in children}

As in adults, IGRAs cannot differentiate between LTBI and active disease in children. Preventive therapy programs optimize cost-effectiveness by targeting populations at greatest risk of TB infection and disease. Prior to initiating preventive therapy, children must complete screening to exclude TB, but confirmation of LTBI is not mandatory. Among young household contacts in TB high-burden settings (in whom the risk of LTBI may be $>40 \%$ [74] ), it is most cost-effective to provide preventive therapy to all child contacts younger than 5 years without testing for LTBI [75]. This approach may also be reasonable for child close contacts in countries with low incidence of TB. However, in most TB low-burden settings, documentation of a positive IGRA or TST result guides the use of preventive therapy in child contacts [6-78].

Microbiological confirmation of child TB is rare due to the challenges of sputum collection, the paucibacillary nature of the disease, and the low yield of diagnostic tests [79]. A systematic review estimates that $75 \%$ of children receive TB treatment based on bacteriologically unconfirmed, clinically diagnosed TB [무]. IGRAs are commonly used in children living in upper income, low TB-burden countries, and the results influence clinical decision making [ $\underline{81}$ ]. Pragmatic use of IGRAs and TST in children have emerged through clinical practice and informed US guidelines [77]. In low-risk, BCG-vaccinated or NTM-exposed children (in whom positive TST results are expected due to adaptive immunity against other mycobacteria), high specificity is desired which makes the use of IGRAs preferable. In young or immunocompromised children with significant risk of TB progression, testing strategies optimize sensitivity by using both an IGRA and a TST; a positive result with either test is considered evidence of LTBI. Guidelines in the United Kingdom 
recommend TST as the first test of LTBI, with use of IGRAs only in children with a negative TST or at times when the TST is unavailable or impractical [묘]. Because several studies have shown that IGRAs are more likely to be indeterminate or negative in children younger than 5 years, current US CDC guidelines recommend the use of TST rather than IGRA in children younger than 5 years [ㄷ]. The WHO preferentially recommends the TST [르] and recommends against the use of IGRAs in TB high-burden settings [루․

\section{CONCLUSIONS}

As the risk for tuberculosis depends on host susceptibility and pathogen exposure, the definition of risk groups for targeted LTBI screening varies substantially over time and is dependent on the geographic region.

While health-care workers in the United States and Western Europe used to be considered a high-risk group for TB as the prevalence of the disease was thought to be high, recent studies have shown that the risk of TB for these workers is low, justifying screening by IGRAs only when a special exposure has occurred, similar to household contacts [42-44]. In people with HIV-infection in countries with a low prevalence of TB, the risk for TB is dramatically reduced in patients who experience sustained undetectable levels of viral replication $[\underline{45}, \underline{84}]$. It is presently unclear whether all HIV-infected patients in these countries should be regularly screened by IGRAs or whether screening should be restricted to the minority who are antiretroviral therapy (ART) naive, are failing HIV-therapy, or have had recent known M. tuberculosis exposure. More than 25\% of patients with chronic renal failure from countries with low incidence of TB have positive IGRA responses despite no substantially increased risk for the development of TB [ $\underline{8}$ ]. These patients should be screened for LTBI in high-incidence countries where they have an increased risk for $M$. tuberculosis exposure. They should not be routinely screened in low-incidence countries where a positive test result in these patients is not related to a substantial risk for the development of tuberculosis.

In order to provide evidence-based recommendations that are valid for specific geographic regions, cohorts of putative risk groups for TB must be followed longitudinally to evaluate the performance of immunodiagnostic testing, the risk for tuberculosis, and the effect of preventive chemotherapy in different groups and regions. Consensus must be reached on the NNT to prevent one case of tuberculosis. This consensus should guide national and international management recommendations. The recommendations that are provided in this review (Table 4) allow guidance using sub-group stratified best evidence.

Without knowledge about the NNT to prevent a case of tuberculosis in different groups and regions there is both the risk of undertreatment and overtreatment and lack of acceptance of preventive therapies [도].

In order to achieve the goal of TB elimination in low-burden countries, prevention of TB must be improved substantially. Without a vaccine that protects individuals exposed to M. tuberculosis better than $M$. bovis BCG, TB prevention strategies must rely on infection control measures and preventive chemotherapy for those individuals with LTBI, who have the highest risk for the progression to active TB [86]. Unfortunately, none of the presently available tests for LTBI offer a high prognostic value. In countries with low incidence for $\mathrm{TB}$, immunodiagnosis is presently the 
most effective measure to identify people with LTBI who should receive preventive chemotherapy to avoid progression to TB. Considering multiple factors when determining individual risk of future TB is attempted in adult algorithms such as the Online TST/IGRA interpreter, which can likely maximize the prognostic capability of available and future diagnostic tools [ㄷ]].

A recent study in a large cohort of adolescents from Africa has identified a 16 gene transcriptomic signature from the peripheral blood that was highly predictive for the development of TB and that appears superior to IGRAs in predicting disease development [7]]. Promising results were validated in 2 independent African cohorts suggesting that the NNT to prevent one case of TB could be lowered to $<10$ by transcript analysis. However, it is presently unclear how well this method will predict the development of TB in individuals from different risk groups in countries with low incidence of TB and how specific such a test will be. Large multinational and multicohort studies are needed to address this question.

While using IGRAs as screening tools for providing preventive chemotherapy for people with positive test results is effective for the individual risk reduction for TB in people from high-risk groups, the effect of screening programs on the overall incidence of TB in low-incidence countries is likely to be low. At times of high global mobility, elimination of TB in low-incidence countries will not be possible by an IGRA-based prevention approach as long as a steep gradient of the burden of TB continues to exist between different geographic regions of the world [요].

\section{ACKNOWLEDGMENTS}

FIND (CMD) has received funding by the CDC under grant agreement 5U2GPS002746-05. CL is supported by the German Center for Infection Research (DZIF). CL reports personal fees from Chiesi, personal fees from Gilead, personal fees from Abbvie, personal fees from MSD, personal fees from Becton Dickinson, personal fees from Janssen, outside the submitted work. BK reports personal fees from Oxford Immunotec, outside the submitted work. MS reports support for investigator initiated research by Qiagen and Oxford Immunotec (test kits free of charge). In addition, MS has a patent pending on cytokine profiling for detection of active tuberculosis. AM and CMD have nothing to disclose.

\section{REFERENCES}

1. Koch R. Die Aetiologie der Tuberculose. Berl Klin Wschr. 1882;19:221-30.

2. World Health Organization. Global tuberculosis report 2016. Geneva, Switzerland: 2016.

3. World Health Organization. Global tuberculosis report 2015. Geneva, Switzerland: 2015 2015. Report No.

4. Nardell EA. Transmission and Institutional Infection Control of Tuberculosis. Cold Spring Harb Perspect Med. 2015;6(2):a018192. PubMed PMID: 26292985. 10.1101/ cshperspect.a018192

5. Zumla A, Raviglione M, Hafner R, von Reyn CF. Tuberculosis. N Engl J Med. 2013;368(8):745-55. PubMed PMID: 23425167. doi: 10.1056/NEJMra1200894

6. Marais BJ, Gie RP, Schaaf HS, Hesseling AC, Obihara CC, Starke JJ, Enarson DA, 
Donald PR, Beyers N. The natural history of childhood intra-thoracic tuberculosis: a critical review of literature from the pre-chemotherapy era. Int J Tuberc Lung Dis. 2004;8(4):392-402. PubMed PMID: 15141729.

7. Abel L, Casanova JL. Genetic predisposition to clinical tuberculosis: bridging the gap between simple and complex inheritance. Am J Hum Genet. 2000;67(2):2747. PubMed PMID: 10882573. Pubmed Central PMCID: PMC1287174. doi: $10.1086 / 303033$

8. Sester M, van Leth F, Bruchfeld J, Bumbacea D, Cirillo DM, Dilektasli AG, Dominguez J, Duarte R, Ernst M, Eyuboglu FO, Gerogianni I, Girardi E, Goletti D, Janssens JP, Julander I, Lange B, Latorre I, Losi M, Markova R, Matteelli A, Milburn H, Ravn P, Scholman T, Soccal PM, Straub M, Wagner D, Wolf T, Yalcin A, Lange C, Tbnet. Risk assessment of tuberculosis in immunocompromised patients. A TBNET study. Am J Respir Crit Care Med. 2014;190(10):1168-76. PubMed PMID: 25303140. doi: 10.1164/ rccm.201405-0967OC

9. Gómez-Reino JJ, Carmona L, Rodrígues Valverde V, Martín Mola E, Montero MD. Treatment of rheumatoid arthritis with tumor necrosis factor inhibitors may predispose to significant increase in tuberculosis risk. A multicenter active-surveillance report. Arthritis Rheum. 2003;48:2122-7.

10. Comstock G, Livesay VT, Woolpert SF. The prognosis of a positive tuberculin reaction in childhood and adolescence. Am J Epidemiol. 1974;99(2):131-8.

11. World Health Organization. The End TB strategy. Geneva, Switzerland: 2014.

12. Gunther G, Lange C, Alexandru S, Altet N, Avsar K, Bang D, Barbuta R, Bothamley G, Ciobanu A, Crudu V, Danilovits M, Dedicoat M, Duarte R, Gualano G, Kunst H, de Lange W, Leimane V, Magis-Escurra C, McLaughlin AM, Muylle I, Polcova V, Popa C, Rumetshofer R, Skrahina A, Solodovnikova V, Spinu V, Tiberi S, Viiklepp P, van Leth F, for T. Treatment Outcomes in Multidrug-Resistant Tuberculosis. N Engl J Med. 2016;375(11):1103-5. PubMed PMID: 27626539. doi: 10.1056/NEJMc1603274

13. Falzon D, Gandhi N, Migliori GB, Sotgiu G, Cox HS, Holtz TH, Hollm-Delgado MG, Keshavjee S, DeRiemer K, Centis R, D'Ambrosio L, Lange CG, Bauer M, Menzies D, Collaborative Group for Meta-Analysis of Individual Patient Data in M-T. Resistance to fluoroquinolones and second-line injectable drugs: impact on multidrug-resistant TB outcomes. Eur Respir J. 2013;42(1):156-68. PubMed PMID: 23100499. Pubmed Central PMCID: PMC4487776. doi: 10.1183/09031936.00134712

14. Erkens CG, Kamphorst M, Abubakar I, Bothamley GH, Chemtob D, Haas W, Migliori GB, Rieder HL, Zellweger JP, Lange C. Tuberculosis contact investigation in low prevalence countries: a European consensus. Eur Respir J. 2010;36(4):925-49. PubMed PMID: 20889463. 36/4/925 [pii] doi: 10.1183/09031936.00201609

15. Mack U, Migliori GB, Sester M, Rieder HL, Ehlers S, Goletti D, Bossink A, Magdorf K, Holscher C, Kampmann B, Arend SM, Detjen A, Bothamley G, Zellweger JP, Milburn H, Diel R, Ravn P, Cobelens F, Cardona PJ, Kan B, Solovic I, Duarte R, Cirillo DM, Lange C, for the TBNET. LTBI: latent tuberculosis infection or lasting immune responses to M. tuberculosis? A TBNET consensus statement. Eur Respir J. 2009;33(5):956-73. PubMed PMID: 19407047. 
16. Stagg HR, Zenner D, Harris RJ, Munoz L, Lipman MC, Abubakar I. Treatment of latent tuberculosis infection: a network meta-analysis. Ann Intern Med. 2014;161(6):419-28. PubMed PMID: 25111745. doi: 10.7326/M14-1019

17. Mendel F. Über intrakutane Tuberkulinanwendung zu diagnostischen Zwecken (Intrakutanreaktion). Beitr Klin Tuberk. 1909;13:139-44.

18. Mantoux C. L'intradermo-réaction à la tuberculine et son interprétation clinique. Presse Méd. 1910;(no 2):10-3.

19. von Pirquet C. Die Allergieprobe zur Diagnose der Tuberkulose im Kindesalter. Wien Med Wochenschr. 1907;57:1370-4.

20. Critselis E, Amanatidou V, Syridou G, Spyridis NP, Mavrikou M, Papadopoulos NG, Tsolia MN. The effect of age on whole blood interferon-gamma release assay response among children investigated for latent tuberculosis infection. J Pediatr. 2012;161(4):632-8. PubMed PMID: 22632878. doi: 10.1016/j.jpeds.2012.04.007

21. Mukherjee A, Saini S, Kabra SK, Gupta N, Singh V, Singh S, Bhatnagar S, Saini D, Grewal HM, Lodha R, Delhi TBSg, Aneja S, Arya T, Bhatnagar S, Chandra J, Dutta A, Doherty T, Friis H, Grewal HM, Hesseling A, Kabra S, Lodha R, Marais B, Mukherjee A, Parashar D, Prajapati S, Purohit K, Saini D, Saini S, Singh RR, Singh S, Singh V. Effect of micronutrient deficiency on QuantiFERON-TB Gold In-Tube test and tuberculin skin test in diagnosis of childhood intrathoracic tuberculosis. Eur J Clin Nutr. 2014;68(1):38-42. PubMed PMID: 24169461. doi: 10.1038/ejcn.2013.216

22. Mandalakas AM, van Wyk S, Kirchner HL, Walzl G, Cotton M, Rabie H, Kriel B, Gie RP, Schaaf HS, Hesseling AC. Detecting tuberculosis infection in HIV-infected children: a study of diagnostic accuracy, confounding and interaction. Pediatr Infect Dis J. 2013;32(3):e111-8. PubMed PMID: 23190784. doi: 10.1097/INF.0b013e31827d77b7

23. Mandalakas AM, Hesseling AC, Chegou NN, Kirchner HL, Zhu X, Marais BJ, Black GF, Beyers N, Walzl G. High level of discordant IGRA results in HIV-infected adults and children. Int J Tuberc Lung Dis. 2008;12(4):417-23. PubMed PMID: 18371268.

24. Stefan DC, Dippenaar A, Detjen AK, Schaaf HS, Marais BJ, Kriel B, Loebenberg L, Walzl G, Hesseling AC. Interferon-gamma release assays for the detection of Mycobacterium tuberculosis infection in children with cancer. Int J Tuberc Lung Dis. 2010;14(6):689-94. PubMed PMID: 20487605.

25. Carvalho AC, Schumacher RF, Bigoni S, Soncini E, Notarangelo L, Apostoli A, Bonfanti C, Cirillo D, Mantegani P, Porta F, Comelli M, Matteelli A. Contact investigation based on serial interferon-gamma release assays (IGRA) in children from the hematology-oncology ward after exposure to a patient with pulmonary tuberculosis. Infection. 2013;41(4):827-31. PubMed PMID: 23575516. doi: 10.1007/s15010-013-0450-y

26. Bumbacea D, Arend SM, Eyuboglu F, Fishman JA, Goletti D, Ison MG, Jones CE, Kampmann B, Kotton CN, Lange C, Ljungman P, Milburn H, Morris MI, Muller E, Munoz P, Nellore A, Rieder HL, Sester U, Theodoropoulos N, Wagner D, Sester M. The risk of tuberculosis in transplant candidates and recipients: a TBNET consensus statement. Eur Respir J. 2012;40(4):990-1013. PubMed PMID: 22496318. doi: $10.1183 / 09031936.00000712$ 
27. Leidl L, Mayanja Kizza H, Sotgiu G, Ernst M, Hirsch C, Goletti D, Toossi Z, Lange C. Relationship of immunodiagnostic assays for tuberculosis and numbers of circulating CD4+ T-cells in HIV infection. Eur Respir J. 2010;35:619-26.

28. Barcellini L, Borroni E, Brown J, Brunetti E, Campisi D, Castellotti PF, Codecasa LR, Cugnata F, Di Serio C, Ferrarese M, Goletti D, Lipman M, Rancoita PM, Russo G, Tadolini M, Vanino E, Cirillo DM. First evaluation of QuantiFERON-TB Gold Plus performance in contact screening. Eur Respir J. 2016;48(5):1411-9. PubMed PMID: 27390280. doi: 10.1183/13993003.00510-2016

29. Hoff ST, Peter JG, Theron G, Pascoe M, Tingskov PN, Aggerbeck H, Kolbus D, Ruhwald M, Andersen P, Dheda K. Sensitivity of C-Tb: a novel RD-1-specific skin test for the diagnosis of tuberculosis infection. Eur Respir J. 2016;47(3):919-28. PubMed PMID: 26677940. doi: 10.1183/13993003.01464-2015

30. Aksenova VA, Klevno NI, Baryshnikova LA, Dolzhenko EN, Iliasova EV, Medvedev S, Lapshina VN, Kavtarashvili SM. [Diaskintest for tuberculosis in children and adolescents]. Tuberk Biolezni Legkih. 2009 (10):13-6. PubMed PMID: 20050055.

31. Kiselev VI, Baranovskii PM, Rudykh IV, Shuster AM, Mart'ianov VA, Mednikov BL, Demin AV, Aleksandrov AN, Mushkin A, Levi DT, Slogotskaia LV, Ovsiankina ES, Medunitsin NV, Litvinov VI, Perel'man MI, Pal'tsev MA. [Clinical trials of the new skin test Diaskintest for the diagnosis of tuberculosis]. Probl Tuberk Bolezn Legk. 2009 (2):11-6. PubMed PMID: 19382637.

32. Litvinov VI, Shuster AM, Slogotskaia LV, Sel'tsovskii PP, Ovsiankina ES, Mushkin A, Vinogradova TI, Levi DT, Bocharova IV, Filippov AV, Stakheeva LB. [Effectiveness of new diagnostic drug Diaskintest in children for tuberculosis diagnostic]. Probl Tuberk Bolezn Legk. 2009 (4):19-22. PubMed PMID: 19514449.

33. Sester M, Sotgiu G, Lange C, Giehl C, Girardi E, Migliori GB, Bossink A, Dheda K, Diel R, Dominguez J, Lipman M, Nemeth J, Ravn P, Winkler S, Huitric E, Sandgren A, Manissero D. Interferon-gamma release assays for the diagnosis of active tuberculosis: a systematic review and meta-analysis. Eur Respir J. 2011;37(1):100-11. PubMed PMID: 20847080. doi: 10.1183/09031936.00114810

34. Zhou XX, Liu YL, Zhai K, Shi HZ, Tong ZH. Body Fluid Interferon-gamma Release Assay for Diagnosis of Extrapulmonary Tuberculosis in Adults: A Systematic Review and Meta-Analysis. Sci Rep. 2015;5:15284. PubMed PMID: 26503802. Pubmed Central PMCID: 4621514. doi: 10.1038/srep15284

35. de Visser V, Sotgiu G, Lange C, Aabye MG, Bakker M, Bartalesi F, Brat K, Chee CB, Dheda K, Dominguez J, Eyuboglu F, Ghanem M, Goletti D, Dilektasli AG, Guglielmetti L, Koh WJ, Latorre I, Losi M, Polanova M, Ravn P, Ringshausen FC, Rumetshofer R, de Souza-Galvao ML, Thijsen S, Bothamley G, Bossink A, Tbnet. False-negative interferon-gamma release assay results in active tuberculosis: a TBNET study. Eur Respir J. 2015;45(1):279-83. PubMed PMID: 25359336. doi: 10.1183/09031936.00120214

36. Zellweger JP, Sotgiu G, Block M, Dore S, Altet N, Blunschi R, Bogyi M, Bothamley G, Bothe C, Codecasa L, Costa P, Dominguez J, Duarte R, Floe A, Fresard I, Garcia-Garcia JM, Goletti D, Halm P, Hellwig D, Henninger E, Heykes-Uden H, Horn L, Kruczak 
K, Latorre I, Pache G, Rath H, Ringshausen FC, Ruiz AS, Solovic I, Souza-Galvao ML, Widmer U, Witte P, Lange C, Tbnet. Risk Assessment of Tuberculosis in Contacts by IFN-gamma Release Assays. A Tuberculosis Network European Trials Group Study. Am J Respir Crit Care Med. 2015;191(10):1176-84. PubMed PMID: 25763458. doi: 10.1164/rccm.201502-0232OC

37. Chee CB, KhinMar KW, Gan SH, Barkham TM, Koh CK, Shen L, Wang YT. Tuberculosis treatment effect on T-cell interferon-gamma responses to Mycobacterium tuberculosis-specific antigens. Eur Respir J. 2010;36(2):355-61. PubMed PMID: 19926734. doi: 10.1183/09031936.00151309

38. Denkinger CM, Pai M, Patel M, Menzies D. Gamma interferon release assay for monitoring of treatment response for active tuberculosis: an explosion in the spaghetti factory. J Clin Microbiol. 2013;51(2):607-10. PubMed PMID: 23175268. Pubmed Central PMCID: 3553895. doi: 10.1128/JCM.02278-12

39. Katiyar SK, Sampath A, Bihari S, Mamtani M, Kulkarni H. Use of the QuantiFERON-TB Gold In-Tube test to monitor treatment efficacy in active pulmonary tuberculosis. Int J Tuberc Lung Dis. 2008;12(10):1146-52. PubMed PMID: 18812044.

40. Ribeiro S, Dooley K, Hackman J, Loredo C, Efron A, Chaisson RE, Conde MB, Boechat N, Dorman SE. T-SPOT.TB responses during treatment of pulmonary tuberculosis. BMC Infect Dis. 2009;9:23. PubMed PMID: 19250549. Pubmed Central PMCID: 2651889. doi: 10.1186/1471-2334-9-23

41. Tameris MD, Hatherill M, Landry BS, Scriba TJ, Snowden MA, Lockhart S, Shea JE, McClain JB, Hussey GD, Hanekom WA, Mahomed H, McShane H, Team MATS. Safety and efficacy of MVA85A, a new tuberculosis vaccine, in infants previously vaccinated with BCG: a randomised, placebo-controlled phase $2 \mathrm{~b}$ trial. Lancet. 2013;381(9871):1021-8. PubMed PMID: 23391465. doi: 10.1016/S01406736(13)60177-4

42. Dorman SE, Belknap R, Graviss EA, Reves R, Schluger N, Weinfurter P, Wang Y, Cronin W, Hirsch-Moverman Y, Teeter LD, Parker M, Garrett DO, Daley CL. Interferon-g release assays and tuberculin skin testing for diagnosis of latent tuberculosis infection in healthcare workers in the United States. Am J Respir Crit Care Med. 2014;189:7787.

43. Slater ML, Welland G, Pai M, Parsonnet J, Banaei N. Challenges with QuantiFERON-TB Gold assay for large-scale, routine screening of U.S. health care workers. Am J Respir Crit Care Med. 2013;188:1005-10.

44. Schablon A, Nienhaus A, Ringshausen FC, Preisser AM, Peters C. Occupational screening for tuberculosis and the use of a borderline zone for interpretation of the IGRA in German healthcare workers. PLoS One. 2014;9(12):e115322. PubMed PMID: 25541947. Pubmed Central PMCID: PMC4277296. doi: 10.1371/journal. pone. 0115322

45. Lange C, van Leth F, Sester M, Tbnet. Viral Load and Risk of Tuberculosis in HIV Infection. J Acquir Immune Defic Syndr. 2016;71(2):e51-3. PubMed PMID: 26761521. doi: 10.1097/QAI.0000000000000834 
46. World Health Organization. Guidelines on the management of latent tuberculosis infection. World Health Organization Document. 2015;WHO/HTM/TB/2015.01:1-33.

47. Geis S, Bettge-Weller G, Goetsch U, Bellinger O, Ballmann G, Hauri AM. How can we achieve better prevention of progression to tuberculosis among contacts? Eur Respir J. 2013;42(6):1743-6. PubMed PMID: 23900989.

48. Sloot R, Schim van der Loeff MF, Kouw PM, Borgdorff MW. Risk of tuberculosis after recent exposure. A 10-year follow-up study of contacts in Amsterdam. Am J Respir Crit Care Med. 2014;190(9):1044-52. PubMed PMID: 25265362. doi: 10.1164/rccm.201406-11590C

49. Hermansen TS, Lillebaek T, Langholz Kristensen K, Andersen PH, Ravn P. Prognostic value of interferon-gamma release assays, a population-based study from a TB low-incidence country. Thorax. 2016;71(7):652-8. PubMed PMID: 27030576. doi: 10.1136/ thoraxjnl-2015-208228

50. Schablon A, Nienhaus A, Ringshausen FC, Preisser AM, Peters C, Staff PO. Correction: Occupational Screening for Tuberculosis and the Use of a Borderline Zone for Interpretation of the IGRA in German Healthcare Workers. PLoS One. 2015;10(11):e0142541. PubMed PMID: 26540199. Pubmed Central PMCID: PMC4634864. doi: 10.1371/journal.pone.0142541

51. Kik SV, Franken WP, Mensen M, Cobelens FG, Kamphorst M, Arend SM, Erkens C, Gebhard A, Borgdorff MW, Verver S. Predictive value for progression to tuberculosis by IGRA and TST in immigrant contacts. Eur Respir J. 2010;35(6):1346-53. PubMed PMID: 19840963. doi: 10.1183/09031936.00098509

52. Sester M, van Crevel R, Leth F, Lange C. Numbers needed to treat to prevent tuberculosis. Eur Respir J. 2016;46(6):1836-8. PubMed PMID: 26621887. doi: 10.1183/13993003.01047-2015

53. Pai M. Serial testing with TB interferon-gamma release assays: toward a nuanced understanding. Chest. 2012;142(6):1366-7. PubMed PMID: 23208326. doi: 10.1378/ chest.12-1208

54. Moses MW, Zwerling A, Cattamanchi A, Denkinger CM, Banaei N, Kik SV, Metcalfe J, Pai M, Dowdy D. Serial testing for latent tuberculosis using QuantiFERON-TB Gold In-Tube: A Markov model. Sci Rep. 2016;6:30781. PubMed PMID: 27469388. Pubmed Central PMCID: PMC4965809. doi: 10.1038/srep30781

55. Nolan CM, Goldberg SV, Buskin SE. Hepatotoxicity associated with isoniazid preventive therapy. A 7-year survey from a public health tuberculosis clinic. JAMA. 1999;281:1014-8.

56. van Hest R, Baars H, Kik S, van Gerven P, Trompenaars MC, Kalisvaart N, Keizer S, Borgdorff M, Mensen M, Cobelens F. Hepatotoxicity of rifampin-pyrazinamide and isoniazid preventive therapy and tuberculois treatment. Clin Infect Dis. 2004;39:48896.

57. Menzies D, Gardiner G, Farhat M, Greenaway C, Pai M. Thinking in three dimensions: a web-based algorithm to aid the interpretation of tuberculin skin test results. Int J Tuberc Lung Dis. 2008;12(5):498-505. PubMed PMID: 18419884. 
58. Lalvani A, Pathan AA, McShane H, Wilkinson RJ, Latif M, Conlon CP, Pasvol G, Hill AVS. Rapid detection of Mycobacterium tuberculosis infection by enumeration of antigen-specific T cells. Am J Respir Crit Care Med. 2001;163:824-8.

59. Mori T, Sakatani M, Yamagishi F, Takashima T, Kawabe Y, Nagao K, Shigeto E, Harada N, Mitarai S, Okada M, Suzuki K, Inoue Y, Tsuyuguchi K, Sasaki Y, Mazurek GH, Tsuyuguchi I. Specific detection of tuberculosis infection: an interferon-gamma-based assay using new antigens. Am J Respir Crit Care Med. 2004;170(1):59-64. PubMed PMID: 15059788. doi: 10.1164/rccm.200402-179OC

60. Harada N, Higuchi K, Yoshiyama T, Kawabe Y, Fujita A, Sasaki Y, Horiba M, Mitarai S, Yonemaru M, Ogata H, Ariga H, Kurashima A, Wada A, Takamori M, Yamagishi F, Suzuki K, Mori T, Ishikawa N. Comparison of the sensitivity and specificity of two whole blood interferon-gamma assays for M. tuberculosis infection. J Infect. 2008;56(5):348-53. PubMed PMID: 18395264. doi: 10.1016/j.jinf.2008.02.011

61. Kirsch S, Thijssen S, Alarcon Salvador S, Heine GH, van Bentum K, Fliser D, Sester M, Sester U. T-cell numbers and antigen-specific T-cell function follow different circadian rhythms. J Clin Immunol. 2012;32(6):1381-9. PubMed PMID: 22797814. doi: 10.1007/ s10875-012-9730-Z

62. Metcalfe JZ, Cattamanchi A, McCulloch CE, Lew JD, Ha NP, Graviss EA. Test variability of the QuantiFERON-TB gold in-tube assay in clinical practice. Am J Respir Crit Care Med. 2013;187(2):206-11. PubMed PMID: 23103734. Pubmed Central PMCID: PMC3570654. doi: 10.1164/rccm.201203-0430OC

63. Andersen P, Munk ME, Pollock JM, Doherty TM. Specific immune-based diagnosis of tuberculosis. Lancet. 2000;356(9235):1099-104. PubMed PMID: 11009160.

64. Millington KA, Innes JA, Hackforth S, Hinks TS, Deeks JJ, Dosanjh DP, Guyot-Revol V, Gunatheesan R, Klenerman P, Lalvani A. Dynamic relationship between IFN-gamma and IL-2 profile of Mycobacterium tuberculosis-specific T cells and antigen load. J Immunol. 2007;178(8):5217-26. PubMed PMID: 17404305.

65. Day CL, Abrahams DA, Lerumo L, Janse van Rensburg E, Stone L, O'Rie T, Pienaar B, de Kock M, Kaplan G, Mahomed H, Dheda K, Hanekom WA. Functional capacity of Mycobacterium tuberculosis-specific $\mathrm{T}$ cell responses in humans is associated with mycobacterial load. J Immunol. 2011;187(5):2222-32. PubMed PMID: 21775682. Pubmed Central PMCID: 3159795. doi: 10.4049/jimmunol.1101122

66. Lalvani A. Counting antigen-specific T cells: a new approach for monitoring response to tuberculosis treatment? Clin Infect Dis. 2004;38(5):757-9. PubMed PMID: 14986263.

67. Denkinger CM, Pai M, Patel M, Menzies D. Interferon-gamma release assay for treatment monitoring of active tuberculosis - An explosion in the spaghetti factory. J Clin Microbiol. 2012. PubMed PMID: 23175268. doi: 10.1128/JCM.02278-12

68. Tagmouti S, Slater M, Benedetti A, Kik SV, Banaei N, Cattamanchi A, Metcalfe J, Dowdy D, van Zyl Smit R, Dendukuri N, Pai M, Denkinger C. Reproducibility of interferon gamma (IFN-gamma) release Assays. A systematic review. Ann Am Thorac Soc. 2014;11(8):1267-76. PubMed PMID: 25188809. doi: 10.1513/AnnalsATS.201405-188OC 
69. Wallis RS, Pai M, Menzies D, Doherty TM, Walzl G, Perkins MD, Zumla A. Biomarkers and diagnostics for tuberculosis: progress, needs, and translation into practice. Lancet. 2010;375(9729):1920-37. PubMed PMID: 20488517. doi: 10.1016/S01406736(10)60359-5

70. Ruhwald M, Ravn P. Biomarkers of latent TB infection. Expert Rev Respir Med. 2009;3(4):387-401. PubMed PMID: 20477330. doi: 10.1586/ers.09.31

71. Zwerling A. T-cell IFN-gamma responses in patients treated for LTBI Int J Tuberc Lung Dis. 2010; Supplement (Proceedings of the Second Global Symposium on Interferon-Gamma Release Assays):18.

72. Hill PC, Brookes RH, Fox A, Jackson-Sillah D, Jeffries DJ, Lugos MD, Donkor SA, Adetifa IM, de Jong BC, Aiken AM, Adegbola RA, McAdam KP. Longitudinal Assessment of an ELISPOT Test for Mycobacterium tuberculosis Infection. PLoS Med. 2007;4(6):e192. PubMed PMID: 17564487.

73. Wilkinson KA, Kon OM, Newton SM, Meintjes G, Davidson RN, Pasvol G, Wilkinson RJ. Effect of Treatment of Latent Tuberculosis Infection on the T Cell Response to Mycobacterium tuberculosis Antigens. J Infect Dis. 2006;193(3):354-9. PubMed PMID: 16388482 .

74. Beyers N, Gie RP, Schaaf HS, Van Zyl S, Talent JM, Nel ED, Donald PR. A prospective evaluation of children under the age of 5 years living in the same household as adults with recently diagnosed pulmonary tuberculosis. Int J Tuberc Lung Dis. 1997;1(1):3843. PubMed PMID: 9441057.

75. Mandalakas AM, Hesseling AC, Gie RP, Schaaf HS, Marais BJ, Sinanovic E. Modelling the cost-effectiveness of strategies to prevent tuberculosis in child contacts in a high-burden setting. Thorax. 2013;68(3):247-55. PubMed PMID: 22717944. doi: 10.1136/thoraxjnl-2011-200933

76. Mazurek GH, Jereb J, Vernon A, LoBue P, Goldberg S, Castro K, Committee IE, Centers for Disease C, Prevention. Updated guidelines for using Interferon Gamma Release Assays to detect Mycobacterium tuberculosis infection - United States, 2010. MMWR Recomm Rep. 2010;59(RR-5):1-25. PubMed PMID: 20577159.

77. Starke JR, Committee On Infectious D, Committee On Infectious D. Interferon-gamma Release Assays for Diagnosis of Tuberculosis Infection and Disease in Children. Pediatrics. 2014;134(6):e1763-73. PubMed PMID: 25422024. doi: 10.1542/peds.20142983

78. National Institute for Health and Clinical Excellence (NICE). Tuberculosis: clinical diagnosis and management of tuberculosis, and measures for its prevention and control. London: National Institute for Health and Clinical Excellence; 2016.

79. Perez-Velez CM, Marais BJ. Tuberculosis in children. N Engl J Med. 2012;367(4):34861. PubMed PMID: 22830465. doi: 10.1056/NEJMra1008049

80. Detjen AK, DiNardo AR, Leyden J, Steingart KR, Menzies D, Schiller I, Dendukuri N, Mandalakas AM. Xpert MTB/RIF assay for the diagnosis of pulmonary tuberculosis in children: a systematic review and meta-analysis. Lancet Respir Med. 2015. PubMed PMID: 25812968. doi: 10.1016/S2213-2600(15)00095-8 
81. Ling DI, Crepeau CA, Dufresne M, Khan S, Quach C, Dendukuri N, Schwartzman K, Menzies D, Lands LC, Pai M. Evaluation of the Impact of Interferon- Gamma Release Assays on Management of Childhood Tuberculosis. Pediatr Infect Dis J. 2012. PubMed PMID: 22828646. doi: 10.1097/INF.0b013e318269d10c

82. World Health Organization. Guidance for national tuberculosis programmes on the management of tuberculosis in children. Geneva, Switzerland2015.

83. World Health Organization. Use of tuberculosis interferon-gamma release assays (IGRAs) in low- and middle-income countries - Policy Statement. Geneva, Switzerland: 2011.

84. Karo B, Haas W, Kollan C, Gunsenheimer-Bartmeyer B, Hamouda O, Fiebig L, German ClinSurv HIVSG. Tuberculosis among people living with HIV/AIDS in the German ClinSurv HIV Cohort: long-term incidence and risk factors. BMC Infect Dis. 2014;14:148. PubMed PMID: 24646042. Pubmed Central PMCID: 3994660. doi: 10.1186/1471-2334-14-148

85. Gutsfeld C, Olaru ID, Vollrath O, Lange C. Attitudes about tuberculosis prevention in the elimination phase: a survey among physicians in Germany. PLoS One. 2014;9(11):e112681. PubMed PMID: 25393241. Pubmed Central PMCID: 4231044. doi: 10.1371/journal.pone.0112681

86. Kaufmann SHE, Lange C, Rao M, Balaji KN, Lotze M, Schito M, Zumla A, Maeurer M. Progress in tuberculosis vaccine development and host-directed therapies - a state of the art review. Lancet Respir Med. 2014;2:301-20.

87. Zak DE, Penn-Nicholson A, Scriba TJ, Thompson E, Suliman S, Amon LM, Mahomed H, Erasmus M, Whatney W, Hussey GD, Abrahams D, Kafaar F, Hawkridge T, Verver S, Hughes EJ, Ota M, Sutherland J, Howe R, Dockrell HM, Boom WH, Thiel B, Ottenhoff TH, Mayanja-Kizza H, Crampin AC, Downing K, Hatherill M, Valvo J, Shankar S, Parida SK, Kaufmann SH, Walzl G, Aderem A, Hanekom WA, Acs, groups GCcs. A blood RNA signature for tuberculosis disease risk: a prospective cohort study. Lancet. 2016;387(10035):2312-22. PubMed PMID: 27017310. doi: 10.1016/S01406736(15)01316-1

88. Allerberger F, Cambau E, Lange C. Joint efforts urgently needed at times of emerging tuberculosis drug resistance. Clin Microbiol Infect. 2016. PubMed PMID: 27592088. doi: 10.1016/j.cmi.2016.08.023

\section{COPYRIGHT}

(C) Pathogens and Immunity 2017

This work is licensed under a Creative Commons Attribution 4.0 International License. To view a copy of this license, visit http://creativecommons.org/licenses/by/4.0/ 